This is a self-archived - parallel published version of this article in the publication archive of the University of Vaasa. It might differ from the original.

\title{
Emergence of new business areas in regional economies through entrepreneurial discovery processes
}

Author(s): Virkkala, Seija; Mariussen, Åge

Title: $\quad$ Emergence of new business areas in regional economies through entrepreneurial discovery processes

Year: $\quad 2018$

Version: Accepted manuscript

Copyright (C)2018 Routledge. This is an Accepted Manuscript of a book chapter published by Routledge in The entrepreneurial discovery process and regional development : new knowledge emergence, conversion and exploitation on 20 December 2018, available online: http://www.routledge.com/978-1-351-273763

\section{Please cite the original version:}

Virkkala, S., \& Mariussen, Å., (2018). Emergence of new business areas in regional economies through entrepreneurial discovery processes. In: Mariussen, Å., Virkkala, S., Finne, H., \& Aasen, T.M., (eds), The entrepreneurial discovery process and regional development : new knowledge emergence, conversion and exploitation (179-196). Routledge. https://doi.org/10.4324/9781351273763 


\title{
Emergence of new business areas in regional economies through entrepreneurial discovery processes
}

\author{
Seija Virkkala and Age Mariussen
}

\section{Introduction}

This chapter connects the theory of entrepreneurial discovery processes (EDP) with the literature on cluster evolution. This connection is made possible through the notion of emergence, complexity approach and structuration. The chapter provides a 'stylised story' of how micro level entrepreneurial discoveries may transform regional economies by creating emergent clusters. The story of this process is summarised in a figure (see Figure 9.1 below), and illustrated by a case (see Box 9.1), which is the emergence of the energy technology cluster in Vaasa, Finland.

In chapters 5 (Alice Lam 2019 in this volume) and 8 (Virkkala 2019 in this volume) hybrid knowledge spaces and connections between knowledge spaces through third space are discussed. In this chapter, we take the nest step and look at regional economic systems. They consist of firms, networks between firms and related institutions. A distinction is made between two types of complex regional economic systems, static and dynamic. A complex and static regional economy is characterised by fragmentation between knowledge spaces (see Virkkala, 2019, Chapter 8 in this volume) created by a fixed division of labour between different specialised communities of expertise, firms and helices (universities, industries and public sector institutions), created by a one-sided focus on cost efficient exploitation of existing knowledge, rather than exploration and ambidexterity (in Chapter 10, Nguyen and Mariussen, 2019). A region with a static system is likely to have a few, highly structured connections to the outside world, say, core companies exporting goods or raw material to a fixed set of customers. A complex and dynamic regional economy is open for new knowledge from outside and new combinations of existing forms of knowledge, through various forms of third space connections. For instance, a Key Enabling Technology like nanotechnology or biotechnology may be provided through trans-national relational knowledge spaces and integrated into the regional domain (see Chapter 11, Mariussen et al., 2019). Entrepreneurial actors may even extend the borders of complex systems, by connecting them to other systems.

Structuration theory and complexity explains micro-macro interrelations. A successful micro level entrepreneurial discovery creates a bottom-up (or upward) causation, which is emergence of new business areas. The new business area reinforces this micro-level pattern of entrepreneurship and growth through mechanisms of downward causation like knowledge spill-overs, market entry of firms, and subsequent agglomeration. A new cluster is born. The new cluster can grow and transform itself through selection of related industries which fits into its path, and memory of how to make industrial grow. It contributes to increased diversification and complexity in the regional economy. At the same time, dynamic complexity is necessary for the entrepreneurial actors initiating EDP. Dynamic complexity can be increased by exploring the possibilities of transnational networks. In order to achieve dynamic complexity, public sector organisations should destabilise the system and encourage exploration. 
The EDP is expected to drive changes of regional development strategies and regional economic structures. These changes involve self-discovery through regional- level analysis and complex micro-level dialogues. According to Aasen (2019) in Chapter 7 in this volume, entrepreneurial discovery involves numerous people being inspired by regional knowledge resources, local characteristics and current trends. During interaction, patterns of discovery may emerge as recurring themes, and also as negotiations over the meaning of such themes. Emergence is one of the key defining characteristics of complex systems. ${ }^{1}$ This chapter complements Aasen's in offering a macro perspective on the complexity approach and by examining what comes through the process after discovery.

This chapter explores the concepts of system and emergence developed in complexity approaches, and to that end, both the regional economy and the regional development policy will be interpreted as complex systems. The complexity approach and the notion of emergence will bring deeper understanding of the interrelationships between micro and macro levels in the EDP, in particular, how micro level discoveries may have macro level impacts and how these macro level impacts influence the micro level, in a way which results in selfreinforcing causal loops in the regional economy.

The chapter describes a regional economy as an emerging complex system, and the policy of discovery as a policy system which, under certain conditions, may be able to bypass rigidities and create new synergies. EDP should be seen as a general idea that is an integral part of smart specialisation policy, but it can also be interpreted in a more general sense and as part of a policy of discovery and exploration.

In the next section, we discuss relevant concepts of complexity thinking; specifically, those of system and emergence. The third section will interpret EDP as three forms of emergence in the place-based strategy of smart specialisation when discovery is territorially embedded. However, in some cases there is insufficient complexity or dynamics to enable micro-level dialogues to catalyse discoveries, and the fourth section of the current chapter addresses a way to create more dynamics. As shown in Chapter 11 (Mariussen et al., 2019), one solution might be scaling up and building transnational networks to create complexities for discoveries and the emergence of new regional and transregional business opportunities (domains). The last section offers some conclusions on the policy implication of the notion of emergence.

\section{System and emergence: regional economy and EDP}

\section{Complex systems}

A system is a group of interdependent elements. The relationships between elements in a social system are nonlinear and based typically on sustained interdependence. But what constitutes a system is a matter of judgment by the actors comprised by the system and also its observers. Systems are not discrete entities, and transitions between system and non-system states occur. Observers may include policy actors who contribute to the definition of a system they study. ${ }^{2}$ Systems may also be more or less integrated. Mechanisms of integration include the self-referential definitions of members, and members' identities. We may differentiate between strongly integrated, strongly self-referential, and strongly demarcated systems, and weakly integrated, weakly self-referential, and weakly demarcated systems (Morçöl, 2012). 
A complex system is open, and it may let other systems in (Byrne and Callaghan, 2014:26). It may also appear to be fragmented. This lack of clear borders makes it into a difficult object. 'A complicated thing can be taken apart into its bits and reassembled from those bits ... A complex one can't be analysed and integrated either in reality or in mathematical representation' (Byrne and Callaghan, 2014:4).

Byrne and Callaghan (2014:17-38) go on to state that complexity rests on a few simple assumptions:

- First, complex systems are not designed top down, they are the result of selforganisation by many autonomous interrelated decision makers.

- Second, complex systems have emergent properties in the sense that they have the capacity to change in new directions.

- Third, in order to do so, complex systems are able to create energy, by increasing the system scale.

- Fourth, complex systems are inherently unstable.

It is difficult to determine the boundaries of a complex system because the boundary between a complex system and its environment is usually dependent on the purpose of the analysis, and not on any intrinsic property of the system itself. Openness is an inherent feature of complex systems. These systems also tend to be dissipative in that they interact with their environments. They are likely to experience a continual inflow and outflow of energy, matter, and information.

Social systems may be seen as actors following routinised trajectories between stations or points in time and space (commuting, labour markets, suppliers and buyers in regional clusters) (Giddens, 1984). A region's prior development shapes current and future trajectories and possibilities for structural transformation and innovation. However, dynamic complexity can be created when actors begin to initiate re-articulations of spatial patterns. Individual and collective actors can reflect and re-articulate current stations and make routes for new trajectories possible. The reflexivity may include the spatio-temporal structures of the complex systems and different spatio-temporal horizons of action. When acted upon this could lead to the reflexive re-organisation of spatio-temporal matrices and to changes in strategies. Entrepreneurial actors may initiate processes which change the trajectories and the position of stations. Space is evolving, the structure is changing. These strategies of reflexive reorganisation of horizons of actions differs from a perspective on regional development and cluster evolution which is seen as unfolding of given technological histories and opportunities within a fixed place.

We can interpret the regional economy as an emergent system. Krugman (1996) described the economic landscape - cities, region, clusters industrial districts, centres, and peripheries - as a complex, self-organising system. Bretagnolle et al. (2009) described the urban system as a multi-level system consisting of micro-level basic units (e.g., individuals, firms, and institutions) that are resident in the city. Here, the meso level corresponds to the city (as a geographical entity), and the macro level is the system of cities, made up of a large number of towns and cities that interact under unified control (in a national political territory or a global economic network). This organisation is shaped by interactions operating on different spatial and temporal scales of observation. 
The regional economy is an unintended outcome of interactions and decisions made by firms, consumers, inhabitants, citizens, public organisations and institutions. The outcomes of these decisions are systems of cities, rural areas and clusters. Emergence is one way of explaining how structure and form arise in the economic landscape, and why place matters in processes of economic change and evolution (Martin and Sunley, 2013). Accordingly, regional economies can be seen as systems that vary to the extent that there are reciprocal and integrated relations between the elements of the system. The system consists of firms, organisations, as well as actors like employees and employers from different helices with connectivity and interconnections. The regional economy as a system can be strongly or weakly integrated and demarcated. Entrepreneurial discoveries can occur spontaneously in a regional economy as an entrepreneurial initiative (Foray, 2015:35) like in the beginning of the energy technology cluster in Vaasa (Box 9.1). However, many regional economies need a policy effort like Research and Innovation Strategies for Smart Specialisation (RIS3) or similar initiatives to expand their economy and identify new activities. This is achieved through a differentiation between clusters seen as on one hand results of structural evolution of technological trajectories, and on the other hand strategies of reflexive reorganisation of horizons of action, in other words, S3. Smart Specialisation is based on a policy system which is seen as differentiated from the basic forms of organisation of interests among firms involved in a cluster. A regional strategy may take different clusters and their wider context into consideration. As we will see below, and in chapter 11, a reflexive reorganisation of space also depends on a differentiation between policy, science based institutions and the economy, in other words, a triple helix.

The second complex system is accordingly a policy system such as RIS3, which might affect the transformation of the regional economy by establishing new business fields and clusters. The relations among actors involved in this complex system are nonlinear and its relations with its elements and with other systems are co-evolutionary. In a policy system, like RIS3 with the EDP as a core method, policies come into being as consequences of the actions and relationships of multiple individual and collective actors. Governmental actors play important roles in policy systems, but they are among many whose actions influence policy outcomes (see Morçöl, 2012), or in the case of EDP discoveries. The context of RIS3 as a policy system is a specific region and its characteristics; however, RIS3 is also part of broader context like the Europe 2020 strategy by the European Union (EU). The boundaries of the RIS3 are not defined ex ante but through social construction and by actors, members or observers (typically researchers or reporters) of the regional alliance for discoveries. The activities of organisations in the discovery alliances are more or less integrated (i.e. reciprocated and reproduced across time and space).

\section{Three forms of emergence}

Martin and Sunley (2013) differentiate between strong and weak emergence and do so by using a division developed by Deacon (2007) to establish first-, second-, and third-order emergence. In first-order emergence, the micro-level properties spontaneously produce a higher-level structure that is called self-organisation. In second-order emergence, the higherlevel structure becomes supervenient as it begins to influence the lower-level properties and serve as an introduction of downward causal effects. These downward effects give an additional dynamic to the upward effects. Third-order emergence extends the second order in two respects, that is, the introduction of selection processes and memory effects. The behaviour of actors incorporates different characteristics, and those characteristics that help them to adapt to the environment, will be selected, represented, and remembered. This means 
that the system will take on an evolutionary character. All lower-level components are, however, not adaptive and some of them may not survive at all; in addition, new components will influence how the macro-structure evolves over time.

Scale is of particular importance to the problem of emergence because an increase in the number of low level components increases opportunities for iterative interaction. Scale effects also work downwards: and an emergent higher-level property, pattern, or element exerts causal power over the lower-level component. Scale is also important in our analysis since the outcome of a micro-level discovery process between many entrepreneurial actors is the domain at the regional level, which can transform the regional economy through the processes of emergence. Smart experiments on the micro level can also lead to a spontaneous EDP (Benner, 2017, see also Chapter 12 by Aasen et al., 2019 in this book).

First- and second-order emergence are common in the spatial economy. The place and space matter in a dual sense. Spatial division of labour is produced by economic agents, but it also influences the behaviours of the same agents (Massey, 1984). Many decisions and activities of firms, workers, consumers, and other agents, including their locational choices, shape the spatial organisation of the economy, and those spatial forms and patterns in turn shape and constrain their behaviours and decisions. The economic landscape can be seen as an emergent feature and it also exerts downward causation on the micro-components on which it supervenes.

Third-level emergence can be examined with the help of the evolutionary economic geography (EEG) which rest on the concepts of path dependence and related variety (or diversity). Competition between firms causes products and routines to be selected that can help firms to be profitable or adaptable (Nelson and Winter, 1982, Boschma and Martin, 2010). Those routines will then be maintained and diffused locally. The second selection mechanism is the existing knowledge base of a region; a particular knowledge base might be an incentive to expand the activities of firms in a specific sector, which will further the specialisation of the economy (Maskell and Malmberg, 1999), which might create path dependence through cumulative causative processes. The clusters, cities and other regional entities can be both the source of path dependence and its outcome. The development and specialisation of a regional economy is an outcome of its own history.

Discoveries of new opportunities such as entrepreneurial discoveries leading to clusters can be viewed to some extent as self-organising systems. The cluster life cycle literature explains how clusters emerge from the micro level to the macro level (Menzel and Fornahl, 2010, Isaksen, 2011, Fornahl and Hassink, 2017). Here, pre-existing diffused and fragmented knowledge present in the economic landscape are integrated. The initial success is likely to reinforce the patterns and the knowledge configurations of the innovation networks which created it. The cluster grows its value chain and its suppliers and connects to supporting institutions, such as universities. At some point, successful solutions are copied by others. This is referred to as a mechanism of downward causation through knowledge spillovers. It leads to the entry of new firms into the expanding new industry. A self-reinforcing mechanism drives the growth of what has now become an agglomeration. Once established as an agglomeration, the new cluster is likely to evolve a mechanism of learning through selection and memory, including formal institutions, cluster organisations, and also its own storytellers, thus remembering what happened and pointing the way forward. (See Box 9.1.) 
We use the notion of emergence to describe the transformation of a regional economy through an entrepreneurial discovery. The transformation can occur spontaneously or as an outcome of a policy like RIS3 with an EDP as a main method of implementation. While it has elements of design, the EDP is not a fully self-organising system, it is an open process and entrepreneurial actors can be invited during the process. In addition, the outcome of the discovery is open and can be seen as emergent.

\section{Forms of emergence and entrepreneurial discoveries}

We present the EDP as a process transforming a regional economy in a stylised way consisting of three different forms of emergence. In reality, the discovery processes might have a variety of paths and means of scaling. Various institutional and other barriers might hinder the practice of discovery in the regions.

\section{Forms of emergence in a regional economy}

The three forms of emergence are outlined by Foray (2015) as a micro-level discovery of a new domain generating spillovers in the regional economy, which can cause agglomeration of firms around the new activity. In this way, the economic growth based on the micro-level entrepreneurial discovery can diffuse from macro-level i.e. regional level stimulating the growth.

Table 9.1 describes the three forms of emergence in the context of the EDP. The first form of emergence from bottom-up (or upward) causation will occur when diffused and fragmented knowledge, including scientific and technological knowledge, is integrated and a new business area (domain) emerges as the result of the process of self-discovery of entrepreneurial actors. The fragmented knowledge can be seen as emergent properties and the new business area as a structure emerging from those properties. It has a system pattern generated from micro-level properties. Patterns of discovery can emerge as recurring themes when entrepreneurial actors interact and negotiate over the meaning of such themes (see Chapter 7, Aasen, 2018). Some of the elements of the discovery can also be based on transnational learning (see Mariussen et al., 2019, Chapter 11 in this volume).

The second form of emergence is downward causation when the nature or properties of the lower-level components are changing to form a new macro level. In the context of EDP, the new macro level pattern, that is, a new business area stimulates micro-level entrepreneurial discoveries and experiments. Foray (2015) lists those mechanisms as knowledge spillovers, entry of firms, and finally agglomeration. The new domain stimulates a specific type of innovation activity (science based, practice based, process, product, etc.). The regional strategy can support the emergence and development of the new business area or renewal of the existing business area through priorities, projects, and experiments. In addition, specific institutions like cluster organisations can be established or the existing institutions can redirect their activities to support the emerging domain.

According to the third form of emergence, there will be evolutionary dynamics in the process due to selection and memory. The impacts of the successful EDP and regional strategies might allow a structural change in the regional economy, for example by creating a new growth path through the process of cumulative causation and learning or diversifying the economy (Foray, 2015:35). Isaksen et al. (2018) (Chapter 2 in this volume) examine the 
possible outcomes of EDP more thoroughly, by differentiating between path extension, path renewal, and new path creation, using empirical cases. There can be selective sampling of influences that reintroduces the parts into different realisations of the system over time. In the case of disintegration or a weakly integrated regional economy, there might be more integration of the process during the time when the EDP is developed. These forms of emergence are illustrated in the context of the fish-farming by Aasen et al. (2019) (Chapter 12 in this volume) and the experience economy in tourism by Løvland and Finne (2019) (Chapter 13 in this volume).

The general framework is illustrated by Table 9.1 below:

\section{Table 9.1 Transforming regional economy through three forms of emergence}

\begin{tabular}{lll}
\hline Forms of emergence & Characteristics & $\begin{array}{l}\text { Regional economy } \\
\text { Role of private entrepreneurs }\end{array}$ \\
\hline $\begin{array}{l}\text { 1st order } \\
\text { Micro-level }\end{array}$ & $\begin{array}{l}\text { Bottom-up (upward) causation } \\
\text { Aggregated system patterns generated } \\
\text { from the micro level }\end{array}$ & $\begin{array}{l}\text { Entrepreneurial discovery of } \\
\text { opportunities, based on self-discovery of } \\
\text { strengths }\end{array}$ \\
$\begin{array}{ll}\text { Dow } \text { order } \\
\text { Macro level }\end{array}$ & $\begin{array}{l}\text { Self-organising emergent phenomena } \\
\text { Amplified macro-level structures which } \\
\text { reinforce micro-level patterns and } \\
\text { configurations }\end{array}$ & $\begin{array}{l}\text { Knowledge spillover, entry of firms, } \\
\text { agglomeration }\end{array}$ \\
& $\begin{array}{l}\text { Selection and memory } \\
\text { Evolutionary dynamics }\end{array}$ & \\
Selective sampling of influences & \\
Structuration & $\begin{array}{l}\text { reintroducing the parts into different } \\
\text { realisations of the system over time }\end{array}$ & $\begin{array}{l}\text { Growth through new path creation, path } \\
\text { renewal, or path extension } \\
\text { Transformation of the regional economy }\end{array}$ \\
& & \\
\hline
\end{tabular}

Source: Based on ideas of Giddens (1984), Cooke (2012), Martin and Sunley (2007), (2013) and Foray (2015)

\section{The role of the public sector in the discoveries}

EDP seldom occurs spontaneously and requires policy processes for effective discovery. Public-sector organisations are in charge of all emerging elements of the RIS3 (Table 9.2). In the self-discovery phase (the first form of emergence), they should analyse the regional economy and its strengths and opportunities together with universities. They should take the initiative, build connections and partnerships between relevant entrepreneurial actors, and organise the discovery process. Public-sector organisations should create conditions of disequilibrium. They have a central role in integrating the relevant entrepreneurial knowledge distributed over firms, universities, clients and users, specialised suppliers and other organisations. After relevant knowledge has been integrated, it should be processed and synthesised in order to formulate and select the key regional priorities for the RIS3. Prioritisation is an interactive process in which public-sector organisations assess potential and then empower those actors most capable of realising that potential. Public-sector actors are not neutral but select the relevant vertical priorities (Foray, 2015). This can be seen as a process of creating disequilibrium instead of equilibrium. In the case of lock-in, the new domains can be searched by encouraging the cross-sectoral co-operation.

In the second phase (downward causation), public-sector actors support the emergence and development of the new business area or renewal of the existing business area through 
priorities, projects and experiments. Determining the policy mix and selecting the projects implementing the strategy can be seen as a process moving from the macro level to the micro level; one in which knowledge diffusion is important. EDP is basically economic experimentation with new ideas and self-organisation.

The third phase includes continuous monitoring of the transformation of the regional economy and experimental learning, which should lead to the better governance of the EDP. The process of self-discovery and EDP should be continuous and the implementation of the RIS3 should be evaluated and monitored and the lessons should be learnt from the experiments. Finally, the RIS3 and its outcomes should be evaluated also in a broader context that is the context of European systems of innovation, as well as the possible context of macro regions.

\section{Table 9.2 The role of public sector in the transformation of regional economy through emergence}

\begin{tabular}{|c|c|c|c|c|}
\hline \multirow[b]{2}{*}{$\begin{array}{l}\text { Forms of } \\
\text { emergence }\end{array}$} & \multirow[b]{2}{*}{ Characteristics } & \multirow[b]{2}{*}{$\begin{array}{l}\text { Economy } \\
\text { Role of private } \\
\text { entrepreneurs }\end{array}$} & \multicolumn{2}{|c|}{ Public sector } \\
\hline & & & $\begin{array}{l}\text { Operational rules } \\
\text { Role of regional } \\
\text { S3 intervention }\end{array}$ & $\begin{array}{l}\text { General principles } \\
\text { Role of EC }\end{array}$ \\
\hline $\begin{array}{l}\text { 1st order } \\
\text { Micro-level }\end{array}$ & $\begin{array}{l}\text { Bottom-up (upward) } \\
\text { causation } \\
\text { Aggregated system } \\
\text { patterns generated from } \\
\text { the micro level }\end{array}$ & $\begin{array}{l}\text { Entrepreneurial } \\
\text { discovery of } \\
\text { opportunity, } \\
\text { based on self- } \\
\text { discovery of } \\
\text { strengths }\end{array}$ & $\begin{array}{l}\text { Creation of } \\
\text { disequilibrium } \\
\text { Analysis, } \\
\text { discovery of } \\
\text { regional strengths } \\
\text { and opportunities } \\
\text { Vision, priorities }\end{array}$ & $\begin{array}{l}\text { Common S3 platform } \\
\text { with general rules and } \\
\text { guidance, encouraging } \\
\text { differentiation of } \\
\text { regional strategies }\end{array}$ \\
\hline $\begin{array}{l}\text { 2nd order } \\
\text { Macro level }\end{array}$ & $\begin{array}{l}\text { Downward causal } \\
\text { effects } \\
\text { Self-organizing } \\
\text { emergent phenomena } \\
\text { Amplified macro level } \\
\text { structures which } \\
\text { reinforces micro-level } \\
\text { patterns and } \\
\text { configurations }\end{array}$ & $\begin{array}{l}\text { Knowledge } \\
\text { spillover, entry } \\
\text { of firms, } \\
\text { agglomeration }\end{array}$ & $\begin{array}{l}\text { Reinforcing } \\
\text { downward } \\
\text { causation } \\
\text { Compensating the } \\
\text { leader, knowledge } \\
\text { diffusion and } \\
\text { policy mix }\end{array}$ & $\begin{array}{l}\text { Differentiation and } \\
\text { interdependence } \\
\text { Diversified innovation } \\
\text { ecosystems } \\
\text { Discovery and } \\
\text { enlargement of borders }\end{array}$ \\
\hline $\begin{array}{l}3 r d \text { order } \\
\text { Structuration }\end{array}$ & $\begin{array}{l}\text { Selection and memory } \\
\text { Evolutionary dynamics } \\
\text { Selective sampling of } \\
\text { influences reintroducing } \\
\text { the parts into different } \\
\text { realisations of the } \\
\text { system over time }\end{array}$ & $\begin{array}{l}\text { Growth } \\
\text { through new } \\
\text { path creation, } \\
\text { path renewal or } \\
\text { path extension } \\
\text { Transformation } \\
\text { of the regional } \\
\text { economy }\end{array}$ & $\begin{array}{l}\text { Experimental } \\
\text { learning } \\
\text { Monitoring, } \\
\text { analysis, better } \\
\text { governance }\end{array}$ & $\begin{array}{l}\text { Self-referential ability } \\
\text { to self-reproduce and } \\
\text { expand }\end{array}$ \\
\hline
\end{tabular}

Source: Based on ideas of Giddens (1984), Cooke (2012), Martin and Sunley (2007), (2013) and Foray (2015)

We can also see the role of the European Commission (EC) from the perspectives of the three phases of emergence. In the first phase the role of EC or S3 platform is to provide general rules and guidance, encouraging differentiation of regional strategies. The second phase (downward causation) is to encourage more diversified innovation ecosystems. 
We can now summarise this discussion based on the literature of clusters and complexity by a stylised model of how EDP create clusters.

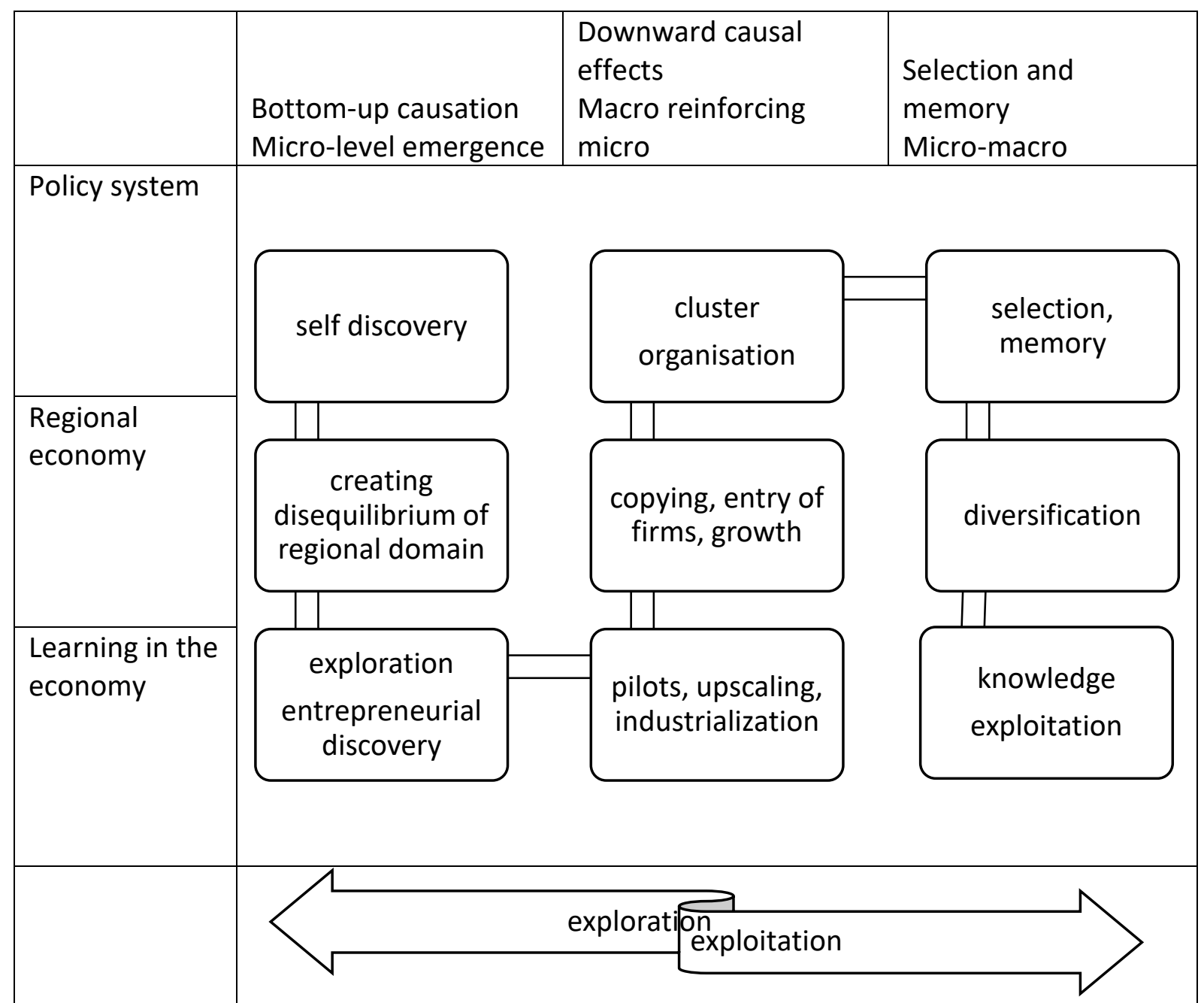

Figure 9.1 The forms of emergence and exploration-exploitation

Source: Own elaboration

In the first phase, a self-discovery in the policy system creates a process of search and disruption in the regional domain, leading to a discovery. This is a process of exploration. In the second phase, the discovery is tested through an industrial pilot, followed by a successful process of upscaling. This leads to entry of new firms, growth, and eventually, in the policy system, setting up of a cluster supporting organisation. In the third phase, the cluster is institutionalised, it builds on experiences, it exploits existing knowledge, and it has a capacity to extend its own existence, renew itself or go back into a new phase of exploration. The regional economy is diversified and more complex.

\section{Box 9.1 Energy technology cluster in Vaasa, Finland}

Sources: (Leinamo, 2006, Ostrobothnia Chamber of Commerce, 2018, Regional Council of Ostrobothnia, 2017, Vasek, 2018) 


\section{Energy technology cluster in Vaasa, Finland}

The Vaasa area is located on the Western coast of Finland, $450 \mathrm{~km}$ north-west of the capital Helsinki. The emergence of the Vaasa energy technology cluster has been organic and firm-led: It can be explained as an entrepreneurial discovery in classical sense and as a process of self-organisation.

\section{Transnational learning, entrepreneurial discovery and entry of new firms}

The history of the energy technology cluster and engineering skills dates back to 1906 when John Wickström started his motor factory with his brother Jacob. John Wickström moved from Vaasa to Chicago to study, and after the studies he established a factory producing boat motors for traffic on Lakes Michigan and Superior. He was an inventor who granted nine patents, also for automobiles.

In Vaasa, and elsewhere in coastal areas in the North, fishing was an important livelihood, but there was no factory to build boat motors and John Wickström saw business opportunities and large virgin markets and moved back to his home country. The motor factory of Wickström brothers made lucrative engines first for boats and later also motors for sawmills, agriculture machines and food industry. The successful business attracted other peoples to the business, and soon Wickström brothers experienced fierce competition in the region. The factories had a large markets; in addition to Nordic countries, the motors were exported to Canada, Spain, Portugal and Japan, for instance.

\section{National entrepreneurship and entrepreneurial discovery in a complex regional domain (first order emergence)}

The second embryonic of the cluster was when the company Wärtsilä came to the region by buying the Onkilahti engineering workshop in Vaasa with its roots in one of Wickström's brothers' factory in 1936. Wärtsilä originates from Karelia where it had a saw mill, iron mill, and a power station. Nowadays, Wärtsilä is a global company providing lifecycle power solutions for the marine and energy markets. Its clients are marine and oil \& gas industry. Wärtsilä is a global energy system integrator offering a flexible internal combustion engine based power plants, utility-scale solar power plants, energy storage \& integration solutions, as well as LNG terminals and distribution systems. Wärtsilä Services supports both shipping and power generation companies.

The third embryonic of the cluster was when Strömberg, manufacturer of various electrical appliances relocated from the capital Helsinki to Vaasa in 1940. Strömberg was acquired by company ASEA in 1988, which is today known as ABB. When ASEA entered the Vaasa region the companies got access to a global marketing network. ABB Vaasa offers solutions for industry automation, and power transmission and distribution, like energy efficient motors, low voltage switches, subsea transformers and grid automation.

\section{Cluster development and cluster organisation (second order emergence)}

The cluster emerged through entry of firms, knowledge spillovers and agglomeration. Since 1990s, the cluster has evolved around the big firms through spin offs, foundation of new firms, and attracting new firms. In this point, the cluster began to influence its members through downward causation giving dynamics for the upward effects. For instance, the supplier network has been developed because of the needs of near and trustful suppliers. The cluster organisation Merinova was established in 1989 and it led several energy related subprogrammes of national expertise programmes in Finland 1995-2014, and later it was active in the sustainable energy solution programme including to INKA-programme. The availability of a strong pool of inputs such as specialised skills and talents has been an important, and the educational institutes have adapted to the cluster by suppling skilled workers to the companies. University of Vaasa established a technical faculty partly to respond the demands of the cluster. 
Memory and selection (third order emergence)

Increased environmental awareness and legislation after 2000 has given further business opportunities to the cluster, and it has evolved to the biggest concentration of energy technology competence in the Nordic Countries. In 2018, the cluster includes about 140 companies, and the manufacturing goes from simple engines to wide range of sophisticated power plants (generators) to high-value and high-tech components for appliances that generate actual energy (windmills, power-plants etc.). The cluster evolves now through memory and selection. The first mechanism is the regional diffusion of profitable routines like new technologies, organizational and managerial innovations, efficient production processes and sub-contractor network. The second selection mechanism is the existing knowledge base of a region, which is an incentive to expansion and further the specialisation reinforcing path dependence through cumulative causative processes. In 2016, Vaasa Energy Business Innovation Centre (VEBIC) was launched as a multidisciplinary research platform involving all University schools, and offering engine and fuel laboratories. It is hosted by University of Vaasa in partnership with regional actors and in cooperation with global research partners. VEBIC is part of cluster policy to enhance research for cluster maintenance and renewal. The regional strategy has supported the growth of the cluster. However, over-specialisation and lock-ins might be future problems in the cluster and continuous entrepreneurial discovery processes at regional level is needed. Smart specialisation strategy aims to diversify the activities based on existing strengths with the help of cross-sectoral platforms.

\section{Scaling: Discoveries within relational spaces}

The complexity approach implies that there has to be a certain level of complexity in the region that enables micro-level dialogues leading to discoveries. The more variety there is of properties like embodied and embedded knowledge, and the more interaction between them (or the actors), the better are the preconditions for the emergence of new business opportunities and domains. However, even if there is enough variety and complexity in the place-based system, it might still be stable. Destabilisation may be created through transnational learning, which can be initiated by public-sector organisations.

For example, regions with economies dominated by exploitation of existing knowledge rather than exploration of new knowledge through discovery might be too rigid and inflexible to change. Networks between people and helices with different types of knowledge may follow strictly standardised definitions. Core companies may be sleeping giants, in that they are large and crucial for the economy, but they focus on exploitation of existing knowledge rather than on exploration. Given these stable frameworks, their regional suppliers may be cultivating and protecting their own unique and internal domains of knowledge defining their position within the network against others. This kind of structure is likely to have clear borders separating insiders from outsiders. Relations are stable and predictable; everybody knows their role in the network. Since the focus is on exploitation, productivity might be high. This type of closed system may seem to be highly integrated and well-functioning, with strong identities among members. Nevertheless, it does not have the dynamics that can support discoveries leading to emerging new opportunities, which would pose a challenge for regional development policy. Nevertheless, the dynamics that can prompt discoveries may have several sources, and not only exogenous ones. 
One solution to this problem is the scaling of the EDP and the networks from a regional basis to become interregional and transnational networks (Mariussen et al., 2016). Emergence can occur in a broader transnational context. One example is the EC initiative to construct thematic partnerships between smart specialised regions, with the aim of encouraging networks to create new institutional frameworks for co-evolution and collaboration between smart specialised regions (see Mariussen et al., 2019 - Chapter 11 in this volume). This effort can broaden the thematic platforms on industrial modernisation, food and agriculture, and energy of the S3 platform. The idea is that the stakeholders in the transnational thematic networks identify shared issues, problems and bottlenecks as well as the methods to address them. This means that new domains might emerge through the entrepreneurial discoveries and interaction of actors in different regions. They form a common transnational knowledge space which has the characteristics of a relational space (see Chapter 8 by Virkkala, 2019 in this volume). This means the networks are based on the cognitive proximity of the participants rather than their geographical proximity. In the transnational discovery process, the fragmented knowledge including the scientific and technological forms embedded in different regions on common issues is first combined and collated, building the new domain (upward causation). In the second phase, the shared new business area (e.g. a value chain) might grow in participating regions through the processes of networks based on pilot-testing in different regions (see Chapter 11), which may lead to knowledge spillovers, the entry of firms, and to agglomeration effects (downward causation). This might extend the innovative ability of both regional ecosystems and the new emerging macro and transnational framework. An example is the development of European Spallation Source in Scania (Skåne), Sweden, which is a European level laboratory where firms from all over Europe can experiment with product development (see Chapter 11).

This EDP in relational space requires facilitators; those might be the coordinating partners of the thematic network or the $\mathrm{EC}$ - in this case, the $\mathrm{S} 3$ platform

\section{Conclusion}

The complexity approach can serve as a general framework to explain economic development that emphasises the relationships and feedback between activities and actors from different scales. Regional development occurs in the context of both the micro-level interaction of individuals, firms, and organisations as well as that of national and transnational levels of activity. This chapter explored the usefulness of the complexity approach and the concept of emergence in the interpretation of the transformation of the economic landscape through EDP. Both the regional economy and the policies of discoveries or the RIS3 can be seen as complex systems and the transformation of a regional economy can be explained through three forms of emergence. The EDP as a form of emergence was presented in an idealised way; in practice, there are many institutional and other barriers preventing or diminishing the preconditions of the discovery process and its impacts on the transformation of a regional economy.

There are still many open questions around the complexity approach in the context of the EDP. For example, the complexity approach emphasises the endogenous interaction of properties - as does the endogenous approach to place-based development - as a source of emergence, but often the changes are external to the regional economies. Regional economies are open economies and embedded in national or global value chains. The emergence approach can be criticised for not placing sufficient emphasis on design and policy (Cooke, 2012). 
The first policy implication of this chapter is that the smart specialisation literature and policy design would benefit from considering a wider variety of properties like embodied and embedded knowledge because the more complex the micro-level components are, the greater the connectivity and interaction between them (or between actors), and thus the better are the prospects for the emergence of new business opportunities and domains. The second policy implication is addressed to the regions with complex but stable economies which need to be destabilised for emergence of new domains. Destabilisation is a challenge for public sector organisations facilitating the RIS3. One way to increase both complexity and destabilisation in regional economies and place-based RIS3s is to encourage transnational learning, which might, for example, come about through transnational thematic networks driven by the S3 platform.

Complex policy systems are multi-causal. According to the complexity approach, the outcome of a policy system like the RIS3 is not linear, and such a policy also often has unintended outcomes (Morçöl, 2012). Moreover, there can be surprising elements owing to an unplanned spatial outcome of a regional development policy like smart specialisation policies, and it is impossible to predict the exact outcomes of policy interventions. However, the discovery process is a combination of deliberate and emergent policy outcomes. Public sector actors have an active role as enablers supporting the discovery process. If there is a negative lock-in in regional economic development due to over-specialisation, the public-sector actors should aim to destabilise the static situation and encourage the exploration of new domains. The uncertainty should be acknowledged in the policy design which supports an experimental learning approach through trial and error as a core of EDP and RIS3.

\section{References}

Aasen, T. M. 2019. Approaching knowledge conversion in entrepreneurial discovery processes from a complex process theory perspective. In: Mariussen, Å., Virkkala, S., Finne, H. \& Aasen, T. M. (eds.) The entrepreneurial discovery process and regional development: New knowledge emergence, conversion and exploitation. Abingdon: Routledge.

Aasen, T. M., Ullern, E. F. \& Mariussen, Å. 2019. Science/practice knowledge interaction in the Norwegian fish farming industry. In: Mariussen, Å., Virkkala, S., Finne, H. \& Aasen, T. M. (eds.) The entrepreneurial discovery process and regional development: New knowledge emergence, conversion and exploitation. Abingdon: Routledge.

Benner, M. 2017. Smart specialisation and cluster emergence: Elements of evolutionary regional policies. In: Fornahl, D. \& Hassink, R. (eds.) The life cycle of clusters. A policy perspective. Cheltenham: Edward Elgar.

Boschma, R. A. \& Martin, R. (eds.) 2010. The handbook of evolutionary economic geography.

Bretagnolle, A., Pumain, D. \& Vacchiani-Marcuzzo, C. 2009. The organization of urban systems. In: Lane, D., Pumain, D., van der Leeuw, S. E. \& West, G. (eds.) Complexity perspectives in innovation and social change. Cham: Springer.

Byrne, D. \& Callaghan, G. 2014. Complexity theory and the social sciences: The state of the art, Abingdon, Routledge.

Cooke, P. 2012. Complex adaptive innovation systems. Relatedness and transversality in the evolving region, Milton Park, Routledge.

Deacon, T. 2007. Three levels of emergent phenomena. In: Murphy, N. C. \& Stoeger, W. R. (eds.) Evolution and emergence: Systems, organisms, persons. Oxford: Oxford University Press.

Foray, D. 2015. Smart specialisation. Opportunities and challenges for regional innovation policy, London, Routledge. 
Fornahl, D. \& Hassink, R. (eds.) 2017. The life cycle of clusters : a policy perspective, Cheltenham: Edward Elgar.

Isaksen, A. 2011. Cluster evolution. In: Cooke, P., Asheim, B., Boschma, R., Martin, R., Schwartz, D. \& Tödtling, F. (eds.) Handbook of regional innovation and growth. Cheltenham: Edward Elgar.

Isaksen, A., Kyllingstad, N., Rypestøl, J. O. \& Schulze-Krogh, A. C. 2019. Entrepreneurial discovery processes in different regional contexts. A conceptual discussion. In: Mariussen, Å., Virkkala, S., Finne, H. \& Aasen, T. M. (eds.) The entrepreneurial discovery process and regional development: New knowledge emergence, conversion and exploitation. Abingdon: Routledge.

Jessop, Bob 2008 State Power A strategic-Relational approach. Polity Press.

Krugman, P. R. 1996. The self organizing economy, Cambridge MA; Oxford, Blackwell.

Luhmann, N. 1995. Social systems, Stanford CA, Stanford University Press.

Løvland, J. \& Finne, H. 2019. The transformation of Lofoten islands into a year-round experience destination. In: Mariussen, Å., Virkkala, S., Finne, H. \& Aasen, T. M. (eds.) The entrepreneurial discovery process and regional development: New knowledge emergence, conversion and exploitation. Abingdon: Routledge.

Leinamo, K. (2006). Valmistettu Vaasassa. Neljä vuosisataa teollisuutta. Vaasa: MedEd publish.

Mariussen, Å., Rakhmatullin, R. \& Hegyi, F. B. 2019. Smart specialisation: Interregional learning via thematic partnerships. In: Mariussen, Å., Virkkala, S., Finne, H. \& Aasen, T. M. (eds.) The entrepreneurial discovery process and regional development: New knowledge emergence, conversion and exploitation. Abingdon: Routledge.

Mariussen, Å., Rakhmatullin, R. \& Stanionyte, L. 2016. Smart specialisation: Creating growth through trans-national cooperation and value chains. Thematic work on the understanding of transnational cooperation and value chains in the context of smart specialisation, Luxembourg, Publications Office of the European Union.

Martin, R. \& Sunley, P. 2013. Forms of emergence and the evolution of economic landscapes. In: Cooke, P. (ed.) Re-framing regional development. Evolution, innovation and transition. London: Routledge.

Maskell, P. \& Malmberg, A. 1999. Localised learning and industrial competitiveness. Cambridge Journal of Economics, 23, 167-185.

Massey, D. 1984. Spatial divisions of labour. Social structures and the geography of production, London, Macmillan.

Menzel, M.-P. \& Fornahl, D. 2010. Cluster life cycles-dimensions and rationales of cluster evolution. Industrial and Corporate Change, 19, 205-238.

Morçöl, G. 2012. A complexity theory for public policy, New York NY, Routledge.

Nelson, R. R. \& Winter, S. G. 1982. An evolutionary theory of economic change, Cambridge MA, Belknap Press of Harvard University Press.

Nguyen, N. \& Mariussen, Å. 2019. Moving beyond related variety, creating firm level ambidexterity for economic growth via entrepreneurial discovery process. In: Mariussen, Å., Virkkala, S., Finne, H. \& Aasen, T. M. (eds.) The entrepreneurial discovery process and regional development: New knowledge emergence, conversion and exploitation. Abingdon: Routledge.

Ostrobothnia Chamber of Commerce (2018). Coastline. https://www.coastline.fi/2018/aboutcoastline/ [accessed 10 July 2018].

Regional Council of Ostrobothnia (2017). Smart Specialisation. https://www.obotnia.fi/regionaldevelopment/smart-specialisation/ [accessed 10 July 2018].

Vasek (2018). Energy Vaasa, the Nordic hub for energy technology. http://energyvaasa.vaasanseutu.fi/energyvaasa-shortly/ [accessed 10 July 2018].

Virkkala, S. 2019. Entrepreneurial discovery process, knowledge creation and knowledge space. In: Mariussen, Å., Virkkala, S., Finne, H. \& Aasen, T. M. (eds.) The entrepreneurial discovery process and regional development: New knowledge emergence, conversion and exploitation. Abingdon: Routledge. 


\title{
Notes
}

\begin{abstract}
${ }^{1}$ Emergence is also the answer of complexity approach to the central problem of social science which is the relation between micro-macro or agency-structure, that is, how the properties and actions of agents/actors affect structural properties and vice versa. This is the so-called transformation problem in sociology, aggregation in economics and the problem of social (or public) choice in political science (Morçöl, 2012:62).

${ }^{2}$ According to (Luhmann, 1995), social systems are self-referential, i.e. they determine how the members/actors define themselves.
\end{abstract}

